\title{
MAPAS CONCEITUAIS: ESTRATÉGIA DE ENSINO/APRENDIZAGEM E FERRAMENTA AVALIATIVA
}

\author{
Nadia Aparecida de Souza* \\ Evely Boruchovitch**
}

RESUMO: O presente ensaio tem por objetivo apresentar uma reflexão sobre as potencialidades do mapa conceitual como estratégia de ensino/aprendizagem e ferramenta avaliativa. Revisitar o referencial teórico relativo à temática possibilitou contemplar a utilidade do mapa conceitual sob diferentes perspectivas: daquele que ensina e daquele que aprende. Valer-se dos mapas conceituais como estratégias de ensino/aprendizagem, também e concomitantemente como ferramenta avaliativa, é criar possibilidades para a organização do conhecimento pela promoção de experiências educativas que provoquem não somente reflexão, busca de compreensão e processamento profundo da informação, mas também o desenvolvimento da autorregulação, da metacognição e do aprender a aprender. Palavras-chave: Estratégias de Ensino e Aprendizagem; Avaliação da Aprendizagem; Mapa Conceitual.

\section{CONCEPTUAL MAPS:}

\section{TEACHING AND LEARNING STRATEGIES AND AN EVALUATIVE TOOL}

ABSTRACT: This essay has the purpose of reflecting upon the potential benefits of conceptual map as teaching and learning strategies and an evaluative tool. To revisit the theoretical framework of this theme made it possible to analyze the utility of conceptual map under different perspectives: the teachers' and the students'. It became clear that the use of conceptual map as teaching and learning strategies, as well as an evaluative tool, leads to knowledge organization by means of promotion of learning experiences which not only generate reflection, comprehension and deep processing of information, but also contributes to the development of metacognition, self-regulation and learning to learn processes.

Keywords: Learning and Teaching Strategies; Learning Assessment; Conceptual Map.

\footnotetext{
* Doutora em Educação pela Universidade Estadual Paulista (UNESP/Marília). Professora do Departamento de Educação da Universidade Estadual de Londrina (UEL); integrante do Núcleo de Estudos e Pesquisas em Avaliação Educacional (NEPAE) e do Grupo de Estudos e Pesquisas em Psicopedagogia (GEPESP) da Universidade Estadual de Campinas (UNICAMP). E-mail: nadia@uel.br

** Ph.D em Educação pela University of Southern California. Professora Associada e Livre-Docente do Departamento de Psicologia Educacional da Faculdade de Educação da Universidade Estadual de Campinas (UNICAMP); Membro do grupo de Estudos e Pesquisas em Psicopedagogia (GEPESP) da Universidade Estadual de Campinas (UNICAMP). Pesquisadora do CNPq. E-mail: evely@unicamp.br
} 


\section{Tecendo os fios}

O mapa conceitual é apenas um meio para se alcançar um fim. Ele pode configurar-se uma estratégia de ensino/aprendizagem ou uma ferramenta avaliativa - entre outras diversas e multifacetadas possibilidades. Todavia, não deve ser compreendido ou efetivado desligado de uma proposição teórica clara e de metas previamente estabelecidas. Consequentemente, à sua adoção e efetivação subjazem perspectivas e opções pessoais relacionadas aos valores, às crenças, às posturas teóricas que conferem sustentação a toda e qualquer prática educativa (ONTORIA, 2005). Ainda, cumpre ressaltar que ele se vincula a um modelo de educação com características bem demarcadas, como: a) ser centrado no aluno e não no professor; b) atender ao desenvolvimento de destrezas e não se conformar apenas com a repetição memorística da informação por parte do estudante; c) pretender o desenvolvimento harmonioso de todas as dimensões da pessoa e não apenas as intelectuais (ONTORIA, 2005; MOREIRA, 2006).

Essa forma de estruturação tem por alicerce a aprendizagem significativa, que consiste na integração de novos conceitos à estrutura cognitiva do aprendiz, "[...] com o propósito de estabelecer aprendizagens interrelacionadas” (RUIZ-MORENO et al., 2007, p. 454), porque é possível relacioná-los com os saberes prévios que a compõem; ou, consoante esclarecem Ausubel, Novak e Hanesian (1980, p. 159), a aprendizagem significativa efetiva-se quando "[...] uma informação nova é adquirida mediante um esforço deliberado por parte do aprendiz em ligar a informação nova com conceitos ou proposições relevantes preexistentes em sua estrutura cognitiva".

Para a ocorrência da aprendizagem significativa, portanto, é essencial determinar o que o aluno já sabe, para, posteriormente, introduzir conceitos novos, em conformidade com a bagagem advinda de seu dia a dia, em consonância com seus conhecimentos prévios. O resultado, repleto de significado, emerge quando o educando, "[...] consciente e explicitamente, estabelece ligações deste novo conhecimento com os conceitos relevantes que já possuía" (SOUSA, 2005, p. 2).

Assim, quando uma aprendizagem é significativa, ela tem o poder de gerar alterações na estrutura cognitiva daquele que aprende, mudando os conceitos preexistentes e formando novas ligações entre eles. 
"Por isso, a aprendizagem significativa é permanente e poderosa, enquanto a aprendizagem desvinculada de um contexto de significado é facilmente esquecida e não é facilmente aplicada em novas situações de aprendizagem ou solução de problemas" (SOUSA, 2005, p. 2).

A aprendizagem significativa, portanto, fundamenta-se no pressuposto de que aprender coisas novas é mais fácil quando estão disponíveis na estrutura cognitiva do indivíduo conceitos prévios, que atuam como pontos de ancoragem (MOREIRA; BUCHWEITZ, 1993; CRUZ, 200X; ONTORIA, 2005). Na verdade, o futuro e o presente parecem depender das ocorrências passadas, das vivências, dos eventos e das situações diversas que ofereceram as bases - os portos de partida - para a efetivação de aprendizagem, almejada em um patamar superior de amplitude e complexidade.

Os conhecimentos prévios, ou subsunçores ou inseridores, afiguram-se nodais para a ocorrência da aprendizagem significativa, pois atuam como indicadores referenciais, como pontos de sustentação para que as novas informações progressivamente adaptem-se à estrutura cognitiva do aprendente. Consequentemente, o novo material informacional será aprendido e retido quando referenciado a conceitos e proposições já disponíveis e que desempenharão a função de pontos de ancoragem.

Subjaz a essa concepção a convicção de que, para aprender mais e melhor, é fundamental ao professor investigar os saberes prévios de seus alunos e estabelecer correlações destes com os novos conhecimentos a serem apropriados, afinal "[...] a análise crítica da matéria de ensino deve ser feita pensando no aprendiz. [pois] de nada adianta o conteúdo ter boa organização lógica, cronológica e epistemológica, e não ser psicologicamente aprendível” (MOREIRA, 1997, p. 18). Cumpre promover condições para que o material proposto não conflite fortemente com aquele já disponível na estrutura cognitiva do educando, ou não se conecte a ela.

A ausência ou a obliteração de conceitos subsunçores - para atuarem como pontos de ancoragem - exige a apresentação, pelo professor, de organizadores prévios, concebidos como materiais introdutórios, mais abstratos, generalizáveis e inclusivos, que terão por tarefa favorecer a relação entre o já dominado pelo aluno e o novo material a ser apropriado. Conforme Moreira (1997, p. 18), os organizadores prévios são comparáveis a um "ancoradouro provisório".

A aprendizagem significativa subordina-se a quatro princípios: diferenciação progressiva, reconciliação integrativa, organização sequen- 
cial e consolidação (MOREIRA, 1997; ONTORIA, 2005). O primeiro princípio, diferenciação progressiva, implica a hierarquização dos conceitos, por sua disposição dos mais abrangentes até os mais específicos, objetivando respeitar duas hipóteses: uma, de que é mais fácil apreender e discriminar um conjunto de características de um corpo de conhecimento quando se tem por ponto de partida os conceitos mais abrangentes, generalizáveis e inclusivos e, por ponto de chegada, aqueles menos abrangentes, generalizáveis e inclusivos; a outra hipótese de que aprender implica a organização hierárquica do conteúdo na estrutura cognitiva (AUSUBEL; NOVAK; HANESIAN, 1978; MOREIRA, 2006). Enquanto implicação para a consecução do ensino decorre a proposição dos conceitos gerais e menos diferenciados de uma disciplina ou unidade informacional, para os específicos e particulares, de tal modo que

[...] um tópico servirá de idéia ou idéias de esteio para os subtópicos em que se subdivide; ou ainda, na sequência dos tópicos, se ordenados com o princípio da diferenciação progressiva, aqueles que vierem antes fornecerão base de assimilação ou esteio para os que vierem depois (FARIA, 1989, p. 29).

O segundo princípio, reconciliação integrativa, envolve o estabelecimento de relações e correlações entre os conceitos a integrarem a hierarquia, pela ampliação no delineamento das distinções e similitudes que os particularizam (AUSUBEL; NOVAK; HANESIAN, 1978; FARIA, 1989; MOREIRA, 2006). Atender esse princípio no contexto educativo pressupõe cuidado na programação do material instrucional a ser utilizado, pois ele deve ser concebido e organizado de maneira a favorecer a exploração de relações entre ideias, a indicação de semelhanças e de diferenças entre elas, bem como harmonizar inconsistências, quer sejam elas reais ou aparentes.

Organização sequencial, terceiro princípio proposto por Ausubel, Novak e Hanesian (1978), implica a disposição sucessiva dos tópicos ou unidades a serem abordados, visando à simplificação do processo de compreensão e apropriação dos conteúdos. Na sala de aula, alguns aspectos devem ser respeitados quanto à organização sequencial dos conteúdos de ensino: logicidade, gradualidade e continuidade. A logicidade evidencia a coerência das escolhas, que, principiando pelos aspectos mais simples da temática, avançam rumo aos mais complexos, traduzindo-se, ao final do percurso previsto, em ampliação dos conhecimentos, das destrezas e das atitudes. A gradualidade, por sua vez, relaciona-se com 
“doses homeopáticas", pela distribuição mais adequada, tanto no concernente à qualidade quanto no relativo à quantidade, das novas informações propostas, principalmente porque estas devem ser apresentadas tendo por base as experiências e os conhecimentos prévios dos alunos. O terceiro aspecto, a continuidade, proporciona conexões entre os conteúdos, de tal modo que estes se complementarão e se integrarão conforme o ensino e a aprendizagem se processam.

Logicidade, gradualidade e continuidade não são apenas aspectos que orientam a organização sequencial na programação dos conteúdos, mas são também "reflexos" do compromisso com a promoção da aprendizagem significativa pela consecução dos princípios da diferenciação progressiva e da reconciliação integrativa.

Finalmente, o princípio da consolidação assevera a importância do domínio, da maestria, da perícia relativamente ao objeto de conhecimento. Saber superficialmente não é suficiente, é preciso saber significativamente. Assim, os conteúdos são real e efetivamente aprendidos e apreendidos quando o educando não somente os reproduz, mas deles se vale para resolver diferentes situações concretas, quando, mais que a transposição linear dos saberes, processa-se sua aplicação em momentos distintos e em ocorrências diversas. No interior da sala de aula, a consolidação exige do professor desvelo na realização de correções, confirmações, promoção de regulações, oferecimento de feedbacks, etc. antes da introdução de outra temática.

O compromisso docente na promoção da consolidação confere ao processo avaliativo sentido e significado diversos daquele que vigeu por muito tempo. Não cumpre ao professor meramente classificar, subordinando pessoas como se fossem coisas, mas desvelar dificuldades de aprendizagem manifestas por seus alunos e, a partir delas, tracejar percursos de ação favoráveis ao domínio, à aprendizagem, à superação, ao desenvolvimento. Não há mais espaço ou tempo a perder responsabilizando outros, geralmente aqueles que o precederam na ação educativa, pelo fracasso ou pelas dificuldades de aprendizagem, mas "arregaçar as mangas" e promover uma aprendizagem mais e mais significativa, porque fundada na bagagem com que o aluno adentra na sala de aula, porque compromissada com seu preparo para a vida e para o exercício da cidadania.

Aprender para a vida. Aprender para valer-se do aprendido na transformação da própria realidade. Aprender significativamente - tarefa complexa e multifacetada que tem encontrado dificuldade em assumir cor 
e sabor de realidade em inúmeras salas de aula. A teoria é árdua e apossar-se dela é trabalhoso. Todavia, uma ferramenta facilitadora para a sua vivência por professores e alunos foi desenvolvida por Novak (FARIA, 1989; MOREIRA; BUCHWEITZ, 1993; ONTORIA, 2005; MOREIRA, 2006): os mapas conceituais, compreendidos como “[...] diagramas hierárquicos que indicam relações entre conceitos. Mais especificamente, podem ser interpretados como diagramas hierárquicos que procuram refletir a organização conceitual de uma disciplina ou parte dela" (MOREIRA, 2006, p. 45-46).

Nos mapas, os conceitos são apresentados no interior de "caixas" ou alguma forma geométrica, enquanto as relações entre eles são especificadas por linhas às quais são agregadas frases explicativas (Figura 1), que procuram aclarar relações proposicionais significativas. Em consequência, para serem representados carecem de três elementos: conceito, proposição e "palavra(s) de enlace" (MOREIRA, 2006; AMORETTI; TAROUCO, 2000; GAVA; MENEZES; CURY, 200X; ONTORIA, 2005; ALMEIDA, 2007).

Conceitos são representações de um objeto pelo pensamento, relativamente à apresentação de suas características gerais, sendo expressos por palavras que os descrevem e particularizam (NOVAK, 1988). Eles podem referir-se a acontecimentos, compreendidos como algo ocorrido e passível de comprovação, ou a objetos, entendidos como elementos existentes e que permitem observação. Ainda, os conceitos podem ser considerados - consoante a perspectiva do indivíduo - como "[...] as imagens mentais que provocam em nós as palavras ou signos com os quais expressamos regularidades" (ONTORIA, 2005, p. 44, destaque do autor).

Figura 1 - Possibilidade de estruturação do mapa conceitual

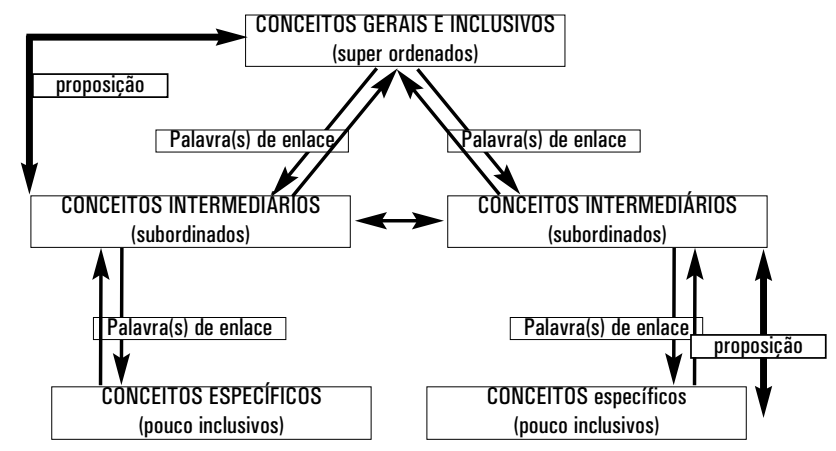


A proposição é composta por dois ou mais conceitos unidos pela(s) "palavra(s) de enlace", formando uma unidade semântica altamente reveladora das conexões e das inter-relações estabelecidas (Figura 2). Conforme Ontoria (2005, p. 45), elas constituem “[...] a menor unidade semântica que tem valor de verdade", porque se apresentam enquanto uma asserção que pode ser subsequentemente asseverada ou negada em algum dos aspectos envolvidos.

Figura 2 - Constituição das proposições

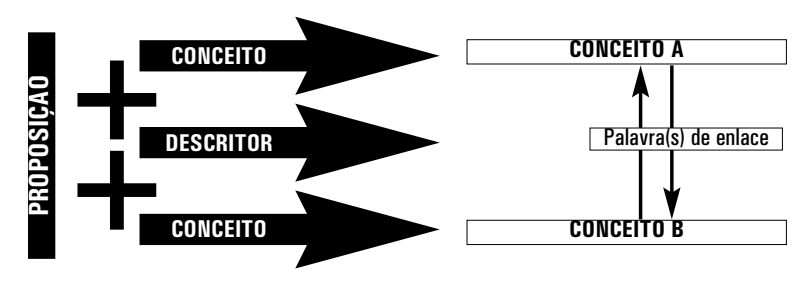

A(s) palavra(s) de enlace ou de ligação, por sua vez, une(m) os conceitos, evidenciando a tipologia da vinculação existente entre eles (SAKAGUTI, 2004; ONTORIA, 2005; MENEGOLLA, 2006; MOREIRA, 2006) (Figura 1). Estas não podem ser quaisquer palavras, porque cumprem a missão de elucidar o tipo de relação existente entre os conceitos que unem, de maneira simples e objetiva - porque almejam conferir legibilidade - ascendente, descendente e horizontal - ao mapa.

Fundamentados na teoria da aprendizagem significativa de David Ausubel, os mapas conceituais são considerados instrumental importante para organizar e representar o conhecimento (Figura 3), pois evidenciam - por meio de proposições ou enunciações elucidativas - as conexões estabelecidas entre ideias-chave (NOVAK, 2006). 
Figura 3 - Mapa conceitual relativo ao tema "Sistema Digestório" elaborado por dois alunos de $7^{\text {a }}$ série, de escola pública estadual paranaense. 2007

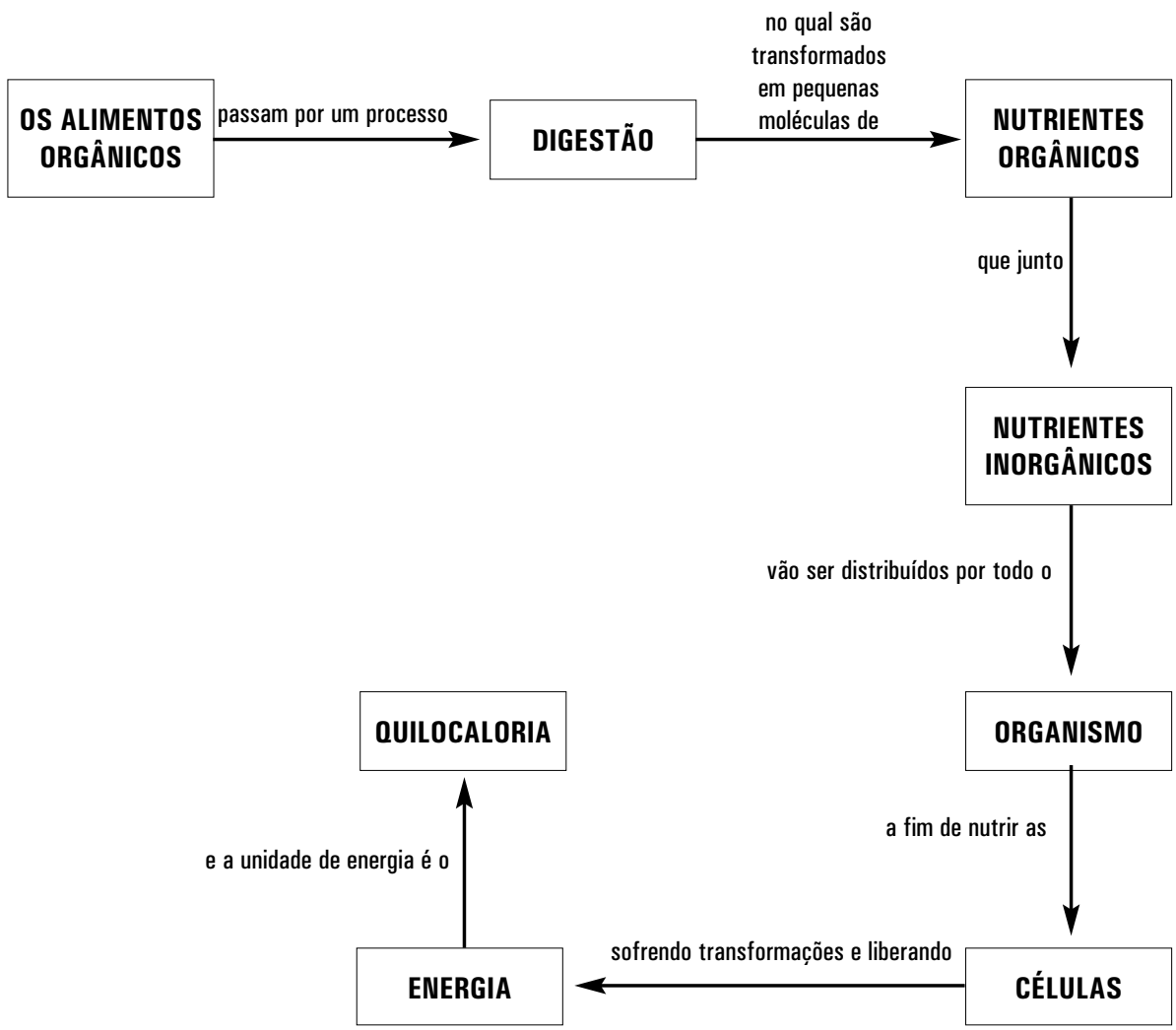

Unidimensionais, quando compostos por listagem de conceitos dispostos verticalmente, ou bidimensionais, quando compostos por listagem de conceitos dispostos vertical e horizontalmente (FARIA, 1989; MOREIRA; MASINI; 2002; ONTORIA, 2005; MOREIRA, 2006), os mapas conceituais podem ser propostos de variadas formas, de maneira que cada um deles é apenas a tradução de um momento daquele que aprende na interação com o objeto do conhecimento.

Os mapas unidimensionais (Figura 4) apresentam-se organizados vertical e linearmente. Normalmente decorrem das primeiras tentativas de elaboração, por isso, oferecem uma visão superficial - se não grosseira - da estrutura conceitual sob foco. Esse tipo de mapa evidencia os arranjos iniciais daqueles que adentram no conhecimento de uma temática e, concomitantemente, de uma ferramenta para representar sua apropriação. 
Figura 4 - Mapa conceitual unidirecional relativo ao tema "Aprendizagem Significativa", elaborado por alunas de curso de Licenciatura em Pedagogia, de universidade pública estadual paulista. 2009

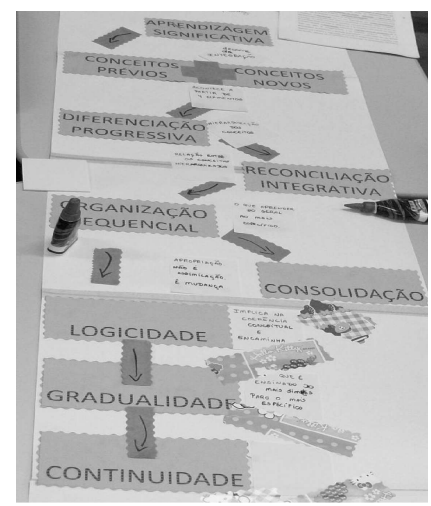

Quando bidimensionais (Figura 5), os mapas conceituais denotam um "passo à frente", pois promovem conexões verticais - que particularizam os mapas unidimensionais - e também horizontais, favorecendo "[...] uma visão mais completa das relações entre os conceitos [...]" (MOREIRA, 2006, p. 46).

Nos mapas, os conceitos mais amplos são apresentados na sua parte superior. O grau de especificidade vai sendo apurado conforme se encaminha rumo à parte inferior, que abarca os conceitos menos inclusivos, conferindo formato e visibilidade à diferenciação progressiva (Figuras 3 e 4). Conforme Moreira (2006),

[...] os conceitos mais gerais e inclusivos aparecem na parte bem superior do mapa. Prosseguindo, de cima para baixo no eixo vertical, outros conceitos aparecem em ordem descendente de generalidade e inclusividade até que, ao pé do mapa, chega-se aos conceitos mais específicos (MOREIRA, 2006, p. 46-47).

Todavia, a leitura do mapa não pode processar-se somente no sentido descendente, mas também no ascendente, bem como horizontalmente - quando os mapas são bidimensionais -, favorecendo a exploração de relações entre os conceitos (COSTAMAGNA, 2001). Alinhados no plano horizontal, são dispostos os conceitos com níveis aproximados de generalidade e inclusividade (Figura 5 - destaque). 
Figura 5 - Mapa conceitual bidimensional relativo ao tema "Aprendizagem Significativa". Elaborado por professores de matemática, física e química que atuam no Ensino Médio, em escola pública estadual paranaense. 2008

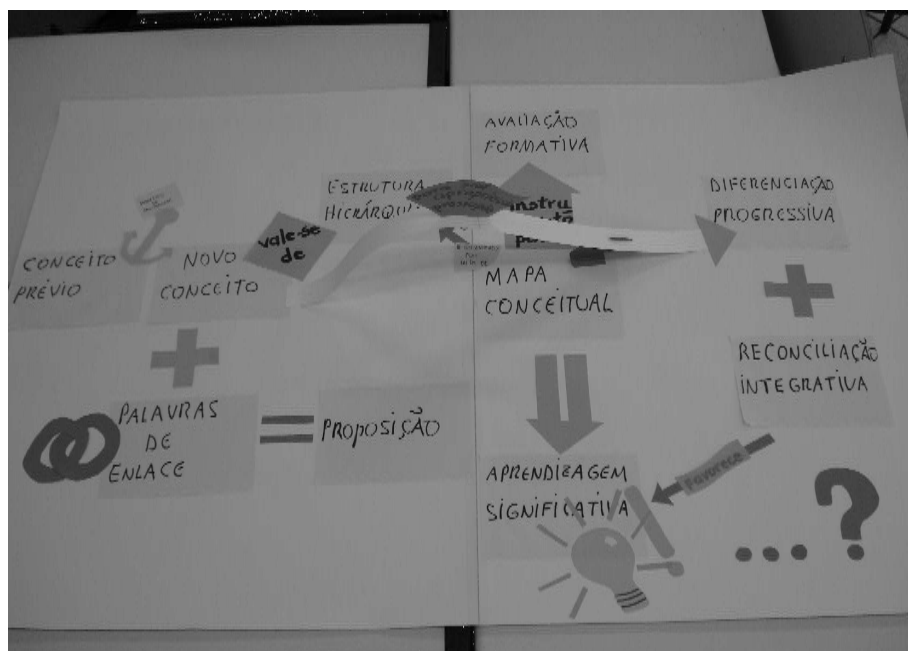

Figura 6 - Mapa conceitual bidimensional relativo ao tema "Aprendizagem Significativa". A reconciliação integrativa é evidenciada pela "ponte" interligando os termos: "novo conceito" e "diferenciação progressiva". Elaborado por professores de matemática, física e química que atuam no Ensino Médio de escola pública estadual paranaense. 2008

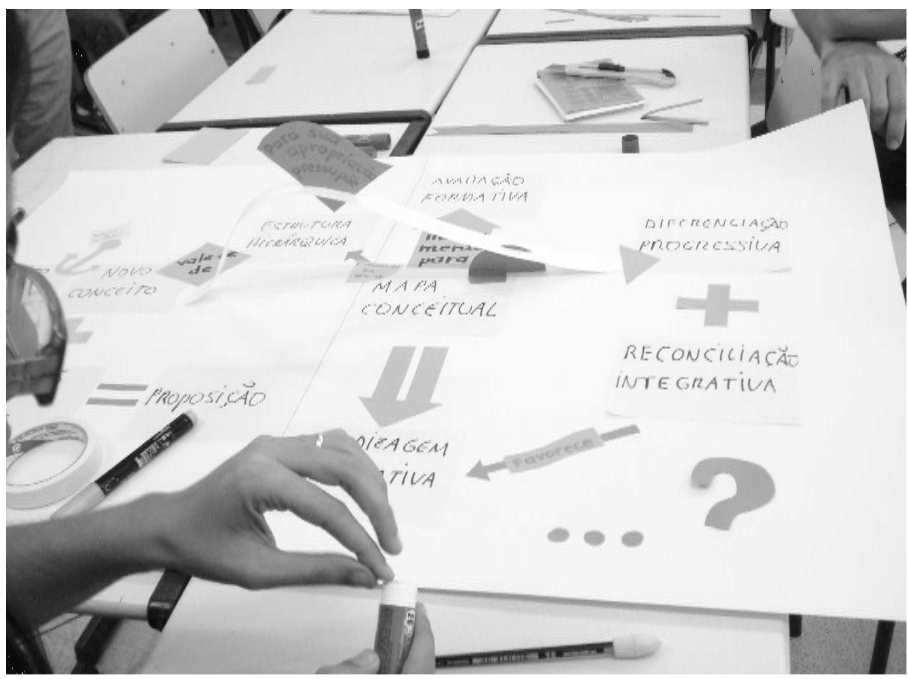


Estabelecer relações entre esses conceitos é mais complexo, principalmente em decorrência de dois fatores: a ordenação hierárquica na dimensão vertical é geralmente priorizada - possivelmente por se afigurar mais singela - e a inter-relação de conceitos demanda reconciliação integrativa (Figura 6), processo mais complexo - pois implica a reorganização da estrutura cognitiva pela aquisição de novos significados, o aclaramento, a diferenciação e a aquisição de estabilidade e distinção de elementos constantes na estrutura cognitiva e percebidos como relacionados. Desse modo, conforme Moreira (1997) destaca

[...] a reconciliação integrativa e a diferenciação progressiva são dois processos relacionados que ocorrem no curso da aprendizagem significativa. Toda aprendizagem que resulta em reconciliação integrativa resultará também em diferenciação progressiva adicional de conceitos e proposições. A reconciliação integrativa é uma forma de diferenciação progressiva da estrutura cognitiva. É um processo cujo resultado é o explícito delineamento de diferenças e similaridades entre ideias relacionadas (MOREIRA, 1997, p. 6).

O mapa conceitual, instrumento facilitador na aprendizagem significativa, é um recurso utilizável de variadas formas no contexto escolar: estratégia de ensino/aprendizagem; organizador curricular, disciplinar ou temático; instrumento avaliativo - e esses são apenas alguns exemplos.

$\mathrm{Na}$ qualidade de estratégia de ensino/aprendizagem, os mapas conceituais apresentam particularidades relevantes: (a) reduzem as preocupações referentes ao ensinar face ao compromisso com a promoção de condições e oportunidades para que os alunos aprendam; (b) possibilitam o rompimento com a "pedagogia magistral” (PERRENOUD, 1999, p. 58) e a assunção de uma pedagogia disposta a respeitar a lógica do educando e a favorecer o desenvolvimento de sua autonomia; (c) predispõem para o trabalho coletivo e colaborativo, no decorrer do qual é fundamental negociar compreensões e significados; (d) valorizam os conhecimentos prévios enquanto fundamento para a apropriação e/ou ampliação de conceitos; (e) evidenciam a diferenciação progressiva e a reconciliação integrativa processadas pelo aprendente; (f) ampliam a possibilidade de os estudantes se valerem de recursos pessoais favoráveis para refletir e compreender seus percursos de aprendizagem; (g) favorecem a consecução de aprendizagem autorregulada. 
A autorregulação implica o exercício de "[...] influência sobre si mesmo", porque os indivíduos se dispõem a "[...] monitorar o seu comportamento, julgá-lo em relação a algum padrão pessoal de mérito e reagir a ele" (BANDURA, 2008, p. 27) ou, também, conforme elucida Perrenoud (1999, p. 97), a gestão, pelo aluno, de “[...] seus projetos, seus progressos, suas estratégias diante de tarefas e obstáculos". Desse modo, consiste em empenhar-se para sobrepujar os problemas e as limitações, independentemente da obtenção de prêmios e recompensas, ou de evitamento de punições e humilhações (Figura 7).

Figura 7 - Mapa conceitual relativo ao tema "Sistema Digestório", que integra o diário pessoal de aluna da $7^{\text {a }}$ série de escola pública estadual paranaense. Os mapas foram construídos por ela em casa, geralmente à noite, para "não esquecer o que fiz na escola". 2007

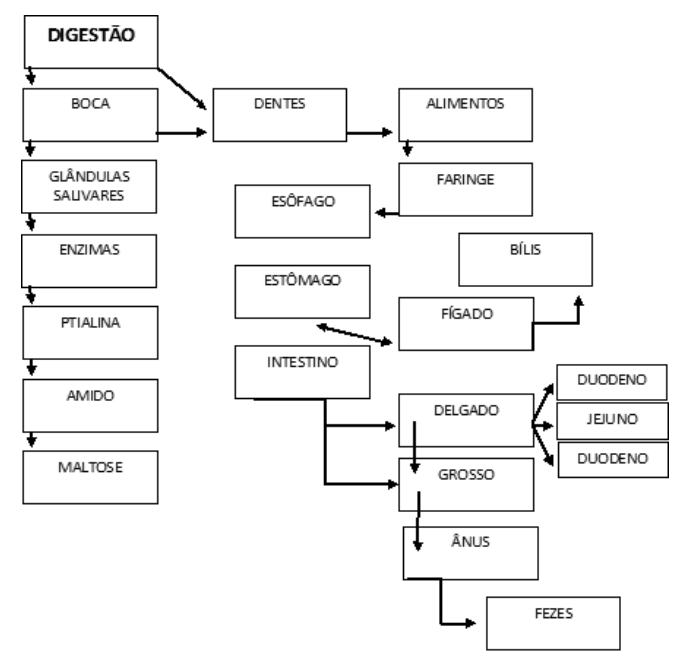

$\mathrm{Na}$ promoção de uma aprendizagem mais autorregulada, os mapas conceituais contribuem para "[...] a aquisição, o armazenamento e/ou a utilização da informação" (BORUCHOVITCH, 1999, p. 3). Os mapas, ao viabilizarem ao aluno: compreender o significado dos conteúdos, relacionando-os aos seus conhecimentos prévios; avaliar continuadamente o que está realizando; e, em consequência, implementar esforços para aprender o que apenas se enuncia como possibilidade, favorecem "processamento profundo", ou aprendizagem por reestruturação, que constitui atividade mental que redunda na "[...] construção de um novo conhecimento em forma de novas proposições", de tal forma que "o novo conhecimento elaborado (isto é, construído e aprendido) não é 
cópia do estímulo recebido pelos sentidos e nem repetição do que já se sabia (Figuras 8, 9 e 10). É uma formulação nova, aliás, marcada pelas peculiaridades do aprendiz, em função de seus conhecimentos prévios [...]" (BZUNECK, 2004, p. 35).

Os mapas conceituais se configuram uma estratégia sofisticada de aprendizagem: a organização. Eles não se limitam ao repassamento de informações, que particularizam as estratégias associativas e o processamento superficial (POZO, 1996), transcendendo também a elaboração, tanto no curso de uma tarefa simples (mapas unidimensionais) quanto complexa (mapas bidimensionais). A organização fundamenta-se, por sua vez, no estabelecimento de relações "[...] internas entre os elementos que compõem os materiais de aprendizagem” (POZO, 1996, p. 191).

Figura 8 - Mapa conceitual elaborado pelo aluno G, aluno de $5^{a}$ série, de escola particular catarinense, a partir do quadro "A Primeira Missa no Brasil". 2007

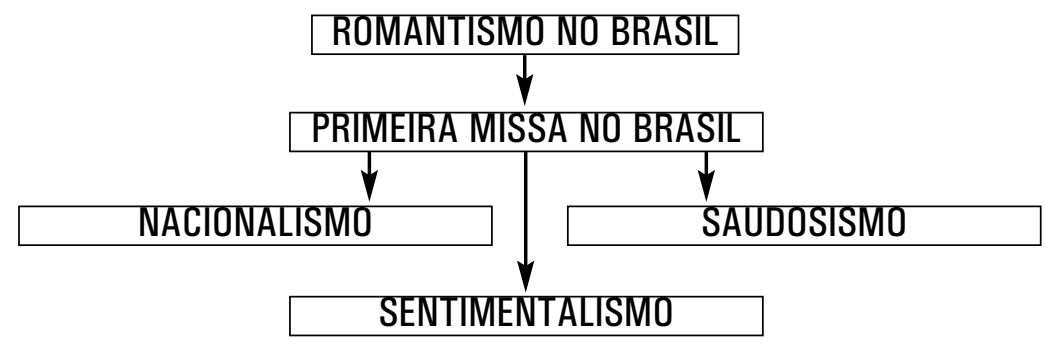

Figura 9 - Releitura do quadro "A Primeira Missa no Brasil" realizada a partir do mapa conceitual elaborado pelo aluno $\mathrm{G}$, de $5^{\mathrm{a}}$ série, de escola particular catarinense. 2007

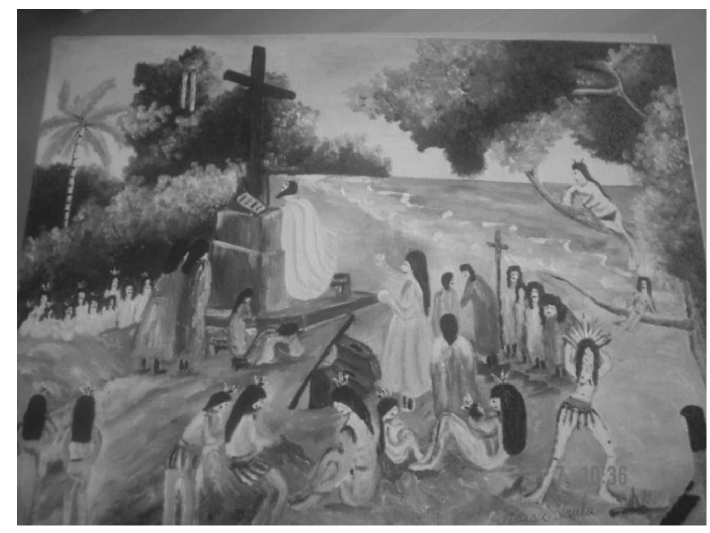


Figura 10 - Mapa conceitual reelaborado pelo aluno $G$, aluno de $5^{\text {a }}$ série de uma escola particular catarinense, após analisar a pintura da tela por ele elaborada.

endo considerado que o primeiro mapa "ficou pobre, porque tem muito mais coisas para colocar", resolveu refazê-lo para melhor retratar o conhecimento apropriado. 2007

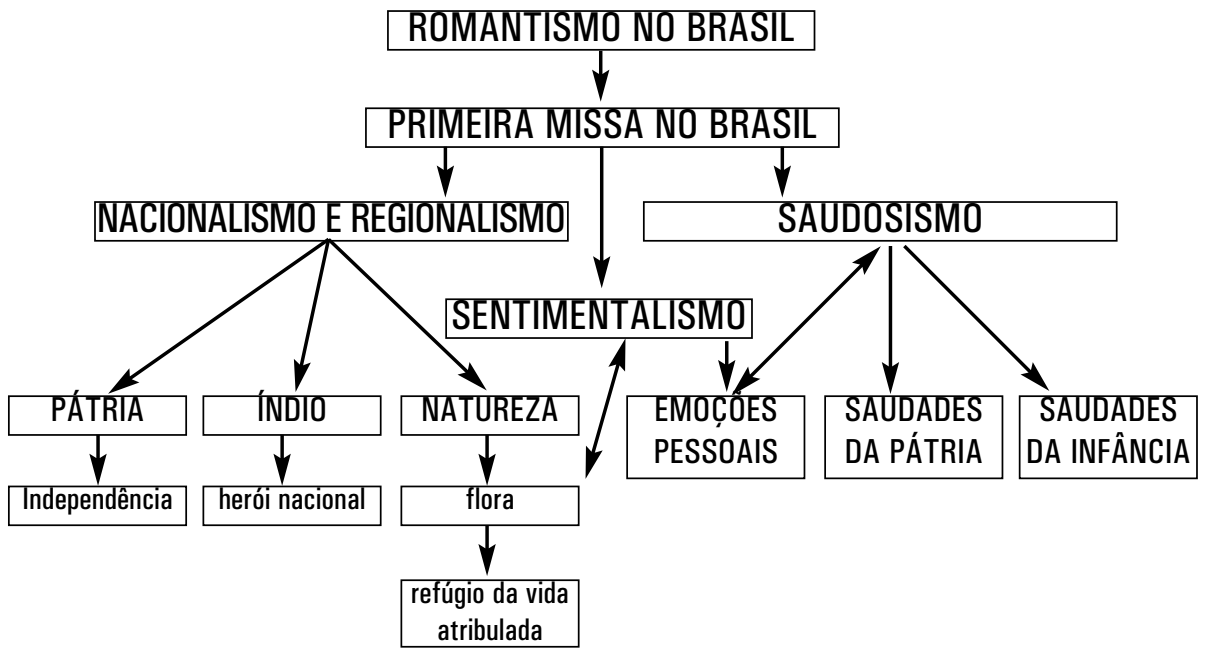

Enquanto estratégias cognitivas de organização do conhecimento, os mapas conceituais possibilitam inúmeros ganhos de natureza metacognitiva, uma vez que mobilizam o aluno no planejamento, monitoramento e regulação do próprio pensamento e das próprias ações (BORUCHOVITCH, 1999). No curso de sua composição, no decorrer de sua confrontação com outros mapas, no tempo de sua reconfiguração, o aluno é levado a refletir criticamente sobre suas realizações e seus percursos cognitivos escolhidos na produção dos resultados alcançados (Figuras 8, 9 e 10). Desse modo, o trabalho com mapas conceituais permite-lhe, contínua e progressivamente, aprender a pensar sobre seu pensamento e sobre suas realizações, a desenvolver a capacidade de conhecer-se - cognitiva, procedimental e emocionalmente, até porque,

A metacognição encaminha para que a reflexão se efetive sobre a própria aprendizagem, sobre o conhecimento necessário para a realização do planejamento, da execução da tarefa e dos processos que levam à percepção do que se sabe e do que ainda se precisa saber. Como a metacognição representa a capacidade que o indivíduo tem de se conhecer e de refletir, esse fator tornase relevante, pois envolve a consciência e a intencionalidade que encaminha para a tomada de decisão (FRISON, 2007, p. 3). 
A autorregulação, sob um foco mais restrito, configura-se enquanto possibilidade de suscitar e ampliar no aprendente a capacidade de gerenciar seus projetos, seus progressos, suas ações em face de diferentes situações ou problemas (PERRENOUD, 1999; ORTEGA, 200X; BORUCHOVITCH, 2004; SILVA; SIMÃO; SÁ, 2004; SOUSA, 2006; BUSTINGORRY; MORA, 2008), todavia, para que ocorra, submete-se à existência de motivo poderoso, de situações verdadeiramente desafiadoras - preferencialmente verdadeiras e mobilizadoras da vontade e da predisposição para aprender, desencadeadoras de uma decisão firme no sentido de sair do plano da aspiração e avançar no plano da realização.

Para que as dificuldades sejam superadas, para que a aprendizagem seja alcançada, é fundamental a proposição de situações de ensino, enquanto desafios ótimos, capazes de despertar interesse ou atender alguma necessidade. A autorregulação não combina com excesso de trabalho e escassez de tempo, que priorizam abordagem superficial das temáticas e a cobrança de sua aprendizagem em rituais estanques, pontuais e que demandam a mera reprodução e o hábito de "estudar para a prova". A autorregulação combina com os mapas conceituais, quer quando empreendidos como estratégia de ensino, quer quando postos a serviço da avaliação formativa.

Quando utilizados como instrumento avaliativo, os mapas conceituais concentram-se na obtenção de informações sobre a estruturação edificada pelo educando para um conjunto de conceitos. Assim, importa determinar os conceitos apropriados e as relações estabelecidas entre eles, interessa precisar como “"...] ele estrutura, hierarquiza, diferencia, relaciona, discrimina e integra conceitos de uma determinada unidade de estudo, tópico, disciplina etc.” (MOREIRA; BUCHWEITZ, 1993, p. 43).

Cada um dos mapas organizados pelo aluno - ou grupo de alunos - oferece evidências sobre o conteúdo e a forma da aprendizagem processada por ele(s). Os mapas não são importantes na promoção da aprendizagem significativa por estarem corretos ou errados, mas por estarem constantemente sendo alterados em consonância com as reestruturações processadas na estrutura cognitiva do educando. A cada novo olhar, o mapa sofre alterações, conferindo dinamicidade e progressividade ao ensino e à aprendizagem (Figuras 11, 12 e 13). 
Figura11 - Início da elaboração do mapa conceitual pelo aluno Ma sobre o "Sistema Digestório".

$7^{\text {a }}$ série de escola pública paranaense. 2007

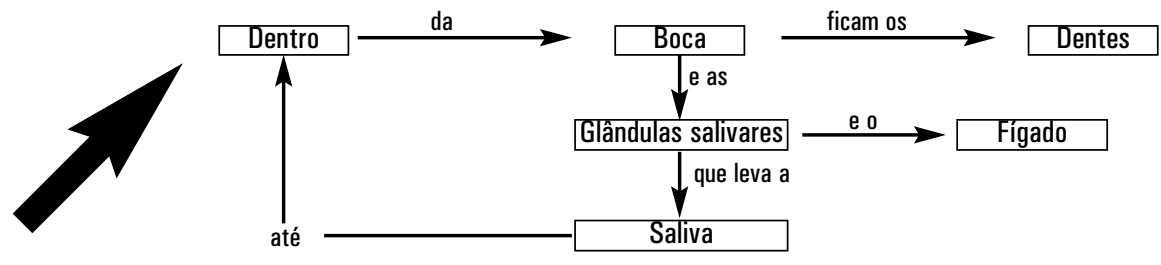

Figura 12 - Diálogo travado entre o Aluno Ma e 0 Aluno K, registrado em protocolo de observação, durante o processo de elaboração do mapa conceitual relativo ao tema "Sistema Digestório". 0 diálogo ocasionou alteraç̃ões que resultaram em outro mapa (Figura 13). $7^{\text {a }}$ série de escola pública paranaense. 2007

0 aluno Ma perguntou para 0 colega sentado ao lado

- Dentro? Não é uma palavra importante?

0 colega respondeu:

- Acho que não. Você pode usar essa palavra para qualquer coisa, não só para a digestão!

- Acho que não? Relutou o Aluno Ma, diante da resposta do colega.

- Então procura no livro. Aconselhou K.

0 Aluno Ma abriu o livro, leu e releu a página que informava o conteúdo, apagou seu mapa e 0 reformulou.

Figura 13 - Mapa reformulado pelo Aluno Ma, após dialogar com o Aluno K sobre 0 tema "Sistema Digestório". 7ª série de escola pública paranaense. 2007

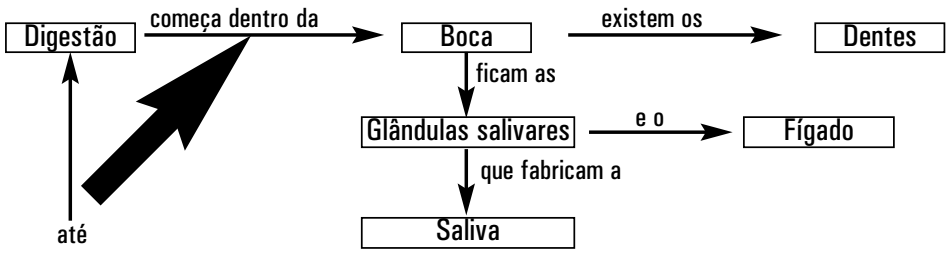

Ao favorecer a determinação dos conhecimentos apropriados pelo aluno, os mapas conceituais orientam as ações e intervenções docentes no aperfeiçoamento do ensino e na ampliação da aprendizagem. Por isso, antes de tudo, a 
[...] análise dos mapas é essencialmente qualitativa. O professor, ao invés de preocupar-se em atribuir um escore ao mapa traçado pelo aluno, deve procurar interpretar a informação dada pelo aluno no mapa a fim de obter evidências de aprendizagem significativa (MOREIRA, 2006, p. 8).

Avaliar formativamente é comprometer-se com o encaminhamento do estudante para percursos que lhe permitam avançar em termos de compreensão dos novos conceitos, aperfeiçoamento dos conceitos prévios e de superação de dificuldades de aprendizagem, justamente porque seu exercício leva o professor a

[...] observar mais metodicamente os alunos, a compreender melhor seus funcionamentos, de modo a ajustar de maneira mais sistemática e individualizada suas intervenções pedagógicas e as situações didáticas que propõe, tudo isso na expectativa de otimizar as aprendizagens (PERRENOUD, 1999, p. 89).

Origem da regulação, que pode ser compreendida como a promoção de ajustes essenciais à consecução da apropriação dos novos conhecimentos, a avaliação formativa tem por diretriz primeira a gestão da aprendizagem, tanto pelo professor quanto pelos alunos. Todavia, gerir pressupõe desvelar, analisar e compreender os conhecimentos dominados, bem como aqueles por serem apropriados (Figuras 14 e 15).

Figura 14 - Diálogo travado entre o Aluno Ma e o Aluno G, registrado em protocolo de observação, durante o processo de elaboração do mapa conceitual relativo ao tema “Sistema Digestório". 0 diálogo ocasionou alterações no mapa elaborado (Figura 13).

$7^{\text {a }}$ série de escola pública paranaense, 2007

Na tentativa de encontrar as "palavras de enlace" para ligar "digestão" a "boca", um dos alunos sugeriu:

- A "digestão" começa na "boca". Os demais colegas que estavam no grupo inicialmente concordaram, até que um deles, 0 Aluno $C$, questionou:

- Mas, todo o processo de digestão começa na boca?

- Eu não sei! Será que todo processo de digestão começa na boca? Indagou o Aluno A.

Alguns deles disseram que sim outros que não, mas a dúvida pairou no ar. Eles começaram a se questionar. Nesse momento, a professora sugeriu que retomassem o livro, indicando um trecho já abordado. Eles, retomando o livro, leram-no mais uma vez na parte que descrevia a digestão na boca, solicitaram alguns esclarecimentos para a professora e concluíram:

- Só o amido que encontramos, por exemplo, na bolacha ou no pão, começa a ser digerido na boca, - disse 0 Aluno $\mathrm{N}$, com 0 que os demais concordaram. 
Figura 15 - Elaboração de mapa conceitual relativo ao tema "Sistema Digestório" por grupo de alunos de $7^{\text {a }}$ série de escola pública paranaense. No decorrer da elaboração, com 0 apoio da professora, eles aprenderam que apenas 0 amido principia a digestão na boca. 2007

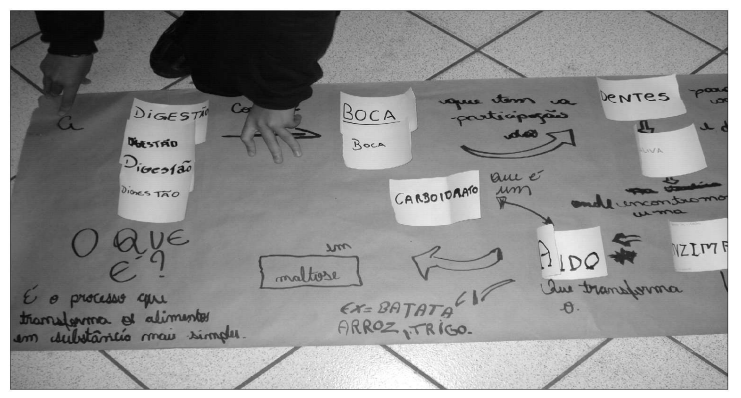

O delineamento do caminho já percorrido pelo educando subordina-se à qualidade e à funcionalidade das tarefas desencadeadoras, ao tornarem mais e mais observáveis o alcance dos objetivos e a consecução da aprendizagem. Portanto, a escolha de atividades capazes de captar e revelar os conceitos dominados, bem como os procedimentos mentais empreendidos, é fundamental (PERRENOUD, 1999; HADJI, 2001; ÁLVAREZ MÉNDEZ, 2002; SILVA; HOFFMANN; ESTEBAN, 2003; COUVANEIRO; REIS, 2007; FERNANDES, 2009). O mapa conceitual, ao facultar ao professor e aos alunos a apreensão desses dois aspectos, configura-se como excelente desencadeador, uma vez que

[...] a ideia principal do uso de mapas na avaliação dos processos de aprendizagem é a de avaliar o aprendiz em relação ao que ele já sabe, a partir das construções conceituais que ele conseguiu criar, isto é, como ele estrutura, hierarquiza, diferencia, relaciona, discrimina e integra os conceitos [...] (GAVA; MENEZES; CURY, 200X, p .2).

Os mapas conceituais, assim sendo, favorecem a consecução de uma avaliação formativa, até porque eles permitem ao professor a compreensão da situação do aluno, ao propiciar a identificação e a análise dos erros, juntamente com a promoção de diagnóstico mais apurado do funcionamento cognitivo envolvido. Em decorrência, podem fornecer indicadores mais precisos para a recomposição do trabalho didático, para a regulação do ensino, visando a possibilitar maior aprendizagem (SOUZA, 2006). 
Os mapas conceituais, utilizados na qualidade de ferramenta avaliativa e observando os propósitos formativos, apresenta como características: (a) promover feedback frequente e de alta qualidade que ativa os processos cognitivos e metacognitivos dos educandos; (b) possibilitar a regulação do ensino e a consequente promoção de variabilidade didática; (c) favorecer a autorregulação da aprendizagem, gerando condições para os alunos responsabilizarem-se progressivamente pelas suas aprendizagens; (d) situar o erro como etapa do processo de aprendizagem, rompendo com a dicotomia saber-não saber e favorecendo a edificação de pontes entre o que se considera importante ensinar e o que é possível aprender; (e) alargar o envolvimento do educando com a gestão de seus percursos de aprendizagem, melhorando sua autoestima e ampliando sua motivação; (f) não segmentar o processo de ensino do processo avaliativo, tornando realidade a crença de que "[...] uma boa tarefa de aprendizagem é ipso facto uma boa tarefa de avaliação”(HADJI, 2001, p. 91).

\section{Amarrando alguns fios...}

Os mapas conceituais configuram-se excelente estratégia de ensino/aprendizagem, bem como ótima ferramenta avaliativa, uma vez que, no curso de sua estruturação e reestruturação, manifestam-se conflitos cognitivos e espaços para a tomada de consciência sobre discrepâncias, problemas, dificuldades, erros - que, quando analisados, confrontados, discutidos, explorados, apresentam-se como espaços de avanços, superações e, por que não, de autorregulações.

Estratégia de ensino/aprendizagem, os mapas conceituais não podem configurar-se rotina, afinal, “[...] dia-a-dia é corrosivo e de tudo que está vivo se deve cuidar” (MORAES, 19XX, p. 1). Desse modo, por mais eficiente, eficaz e pertinente que se configure dada estratégia, seu valor é relativizado frente à necessidade de proceder à variabilidade didática, respeitando os diferentes ritmos e modos de aprender dos estudantes.

Ferramenta avaliativa, os mapas conceituais possibilitam ao professor e aos alunos a percepção quanto à identificação e à apropriação dos conceitos mais relevantes em um contexto informacional, à assertividade das relações estabelecidas entre eles, bem como ao delineamento da quali- 
dade das alterações processadas na estrutura cognitiva do aprendente. E, mais importante, tal não advém de preocupação com a produção de escores, mas do compromisso formativo de proceder à regulação do ensino tarefa do professor - e à autorregulação da aprendizagem - ofício do aluno. Valer-se dos mapas conceituais como estratégia de ensino/ aprendizagem e, também e concomitantemente, como ferramenta avaliativa, torna possível acompanhar o aluno no decurso de processos diversificados e simultâneos: "[...] de aprender (buscar novas informações, de aprender a aprender (refletir sobre procedimentos de aprendizagem), de aprender a conviver (interagir com os outros), de aprender a ser (refletir sobre si próprio enquanto aprendiz)" (HOFFMANN, 2001, p. 139).

Valer-se dos mapas conceituais como estratégia de ensino/ aprendizagem e, também e concomitantemente, como ferramenta avaliativa, é assumir o compromisso com a promoção de experiências educativas que provoquem reflexão e busca de compreensão relativamente aos conceitos ainda em construção, até porque o erro passa a configurar-se indicador diagnóstico a ser interpretado para orientar ações destinadas à promoção de superações e avanços.

Não há repetições ou linearidade no trabalho com mapas conceituais. Cada produção é uma surpresa, porque única naquilo que representa enquanto revelação de um percurso de aprendizagem e de uma estrutura edificada - mesmo quando em permanente reedificação. Talvez a única constância do trabalho com mapas conceituais seja a inconstância, afinal, descobertas, dúvidas, permanências, avanços, retomadas, embaraços, ultrapassagens apresentam-se a cada momento.

Os mapas conceituais relativizam os pontos de chegada, sem os depreciar ou negar, no reconhecimento do valor de acompanhar o percurso, observando atentamente os pontos de passagem, quando afirmam que a aprendizagem é um processo permanente e individual, quando proclamam que a aprendizagem é uma experiência única e singular vivenciada pelo educando, mesmo quando em solidariedade com outros.

Estratégia de ensino/aprendizagem e ferramenta avaliativa, os mapas conceituais atendem à exigência de voltar os olhos para o que já foi, no intuito de aferir o quanto já se avançou em direção ao almejado. Afinal, o passado revela as superações e confere - quiçá - forças e vontade de seguir em frente, na expectativa e na certeza de surpresas inerentes ao inesperado que é aprender. 


\section{Referências}

ALMEIDA, L. R. M. Avaliação formativa no contexto da construção do mapa conceitual. Sitientibus, Feira de Santana, n. 36, p. 175-195, jan./jul. 2007. Disponível em: <http://www.uefs.br/sitientibus/pdf/36/avaliacao_formativa_no_contexto_da_construcao_do_mapa_conceitual.pdf $>$. Acessado em: 10 jan. 2009.

ÁLVAREZ MÉNDEZ, J. M. Avaliar para conhecer. Examinar para excluir. Porto Alegre: Artmed, 2002.

AMORETTI, M. S. M.; TAROUCO, L, M. R. Mapas conceituais: modelagem colaborativa do conhecimento. Informática na Educação: teoria \& prática, PGIE/UFRGS, v. 3, n. 1, set. 2000. Disponível em: <www.rau-tu.unicamp.br/nou-rau/ead/document/ ?down=12>. Acessado em: 20 jan. 2009.

AUSUBEL, D. P.; NOVAK, J. D.; HANESIAN, H. Psicologia Educacional. Rio de Janeiro: Interamericana, 1980.

BZUNECK, J. A. Aprendizagem por processamento de informação: uma visão construtivista. In: BORUCHOVITCH, E.; BZUNECK, J. A. (Orgs.). Aprendizagem: processos psicológicos e o contexto social da escola. Petrópolis, RJ: Vozes, 2004, p. 17-54.

BORUCHOVITCH, E. Estratégias de aprendizagem e desempenho escolar: considerações para a prática educacional. Psicolologia: reflexão e crítica, Porto Alegre, v. 12, n. 2, 1999. Disponível em: <http://www.scielo.br/scielo.php?pid=S0102-79721999000200008\& script $=$ sci_arttext\&tlng=pt $>$. Acessado em 10 dez. 2008.

BORUCHOVITCH, E. A auto-regulação da aprendizagem e a escolarização inicial. In: BORUCHOVITCH, E.; BZUNECK, J. A. (Orgs.). Aprendizagem: processos psicológicos e o contexto social da escola. Petrópolis, RJ: Vozes, 2004, p. 55-88.

BUSTINGORRY, S. O.; MORA, S. J. Metacognicion: um camino para aprender a aprender. Estudos psicológicos XXXIV, Valdívia, 200X, n. 1, p.187-197. Disponível em:<http://www.scielo.cl/pdf/estped/v34n1/art11.pdf>. Acessado em: 10 abr. 2009.

COSTAMAGNA, A. M. Mapas conceptuales como expresión de procesos de interrelación para evaluar la evolución del conocimiento de alumnos universitarios. Enseñanza de lãs Ciencias, Barcelona, v. 16, n. 2, p. 309-318, 2001.

CRUZ, C. C. A teoria cognitivista de Ausubel. Campinas, 200X. Disponível em: <http://www. robertexxto.com/archivo3/a_teoria_ausubel.htm>. Acessado em 5 fev. 2009.

COUVANEIRO, C. S.; REIS, M. A. D. Avaliar, reflectir, melhorar. São Paulo: Instituto Piaget, 2007.

BANDURA, A. A evolução da teoria social cognitiva. In: BANDURA, A.; AZZI, R. G.; POLYDORO, S. Teoria social cognitiva: conceitos básicos. Porto Alegre: Artmed, 2008, p. $15-41$.

FARIA, W. de. Aprendizagem e planejamento de ensino. São Paulo: Ática, 1989.

FERNANDES, D. Avaliar para aprender: fundamentos, práticas e políticas. Marília, SP: EdUNESP, 2009.

GAVA, T. B. S.; MENEZES, C. S. de; CURY, D. Aplicações de mapas conceituais na educação como ferramenta metacognitiva. Vitória, 200X. Disponível em: <http://www.nte-jgs.rctsc.br/mapas.htm>. Acessado em: 22 jan. 2009.

HADJI, C. A avaliação desmistificada. Porto Alegre: ArtMed, 2001.

HOFFMANN, J. Avaliar para promover: as setas do caminho. Porto Alegre: Mediação, 2001. 
MENEGOLLA, A. M. Mapas conceituais como instrumento de estudo na matemática. 2006. Dissertação (Mestrado em Educação em Ciências e Matemática) - Faculdade de Educação em Ciências e Matemática, Universidade Católica do Rio Grande do Sul, Porto Alegre, 2006.

MORAES, V. Planta baixa.19XX. Disponível em: < http://letras.terra.com.br/viniciusde-moraes/86865/>. Acessado em 15 maio 2009.

MOREIRA, M. A.; BUCHWEITZ, B. Novas estratégias de ensino e aprendizagem: os mapas conceptuais e o Vê epistemológico. Lisboa: Plátano, 1993.

MOREIRA, M. A. Mapas conceituais e aprendizagem significativa. Porto Alegre, 199X Disponível em: <http://www.if.ufrgs.br/ moreira/mapasport.pdf>. Acessado em 5 fev. 2009.

MOREIRA, M. A.; MASINI, E. F. S. Aprendizagem significativa: a teoria da aprendizagem de David Ausubel. 2 ed. São Paulo: Centauro, 2002.

MOREIRA, M. A. A teoria da aprendizagem significativa e sua implementação em sala de aula. Brasília: Universidade de Brasília, 2006.

NOVAK, J. D. Aprendiendo a aprender. Barcelona: Marínez Roca, 1988.

NOVAK, J. D. The teory underlying concept maps and how to construct them. Pensacola, 2008. Disponível em: < http://cmap.ihmc.us/Publications/ResearchPapers/ TheoryUnderlyingConceptMaps.pdf >. Acessado em: 6 jan. 2009.

ONTORIA, A. Mapas conceituais: uma técnica para aprender. São Paulo: Loyola, 2005.

ORTEGA, E. M. Aprender a aprender: una competencia básica entre las básicas. Madrid, 200X.Disponível em:<http://www.edu.gva.es/consell/docs/jornadas/conferenciaelenamarti.pdf $>$. Acessado em 30 abr. 2009.

PERRENOUD, P. Avaliação: da excelência à regulação das aprendizagens - entre duas lógicas. Porto Alegre: Artmed, 1999.

POZO, J. I. Estratégias de Aprendizagem. In: COLL, C; PALÁCIOS, J.; MARCHESI, A. (Orgs.). Desenvolvimento psicológico e educação: psicologia da educação. Porto Alegre: Artmed, 1996. RUIZ-MORENO, L.; SONZOGNO, M. C.; BATISTA, S. H. S.; BATISTA, N. A. Mapa conceitual: ensaiando critérios de análise. Ciência \& Educaşão, Bauru, v. 13, n. 3, p. 453463, 2007. Disponível em: <http://www2.fc.unesp.br/cienciaeeducacao/index.php>. Acessado em: 12 nov. 2008.

SAKAGUTI, S. T. Mapas conceituais e seus usos: um estudo da literatura. 2004. Dissertação (Mestrado Profissional) - Instituto de Computação, Universidade Estadual de Campinas, Campinas, 2004.

SILVA, J. F. da; HOFFMANN, J.; ESTEBAN, M. T. (Orgs.). Práticas avaliativas e aprendizagens significativas: em diferentes áreas do currículo. Porto Alegre: Mediação, 2003.

SILVA, A. L. da; SIMÃO, A. M. V.; SÁ, I. A auto-regulação da aprendizagem: estudos teórico e empíricos. Intermeio, Campo Grande, v. 10, n. 19, jan./jun. 2004. Disponível em:<http://www.propp.ufms.br/poseduc/revistas/intermeio/intermeio19.html>. Acessado em: 12 jul. 2008.

SOUSA, P. M. L. de Aprendizagem auto-regulada no contexto escolar: uma abordagem motivacional. Psicologia.com.pt, ago. 2006. Disponível em: <http://www.psicologia. com.pt/artigos/textos/A0295.pdf>. Acessado em: 12 Jul 2008.

SOUZA, N. A. A função pedagógica do erro. III CONGRESSO INTERNACIONAL EM AVALIAÇÃO EDUCACIONAL. Anais... Fortaleza: ABAVE, p. 215-246, 2006. CD-ROM. 


\section{Nota}

${ }^{1}$ Estudo que integra pesquisa maior, realizada com apoio PROCAD - CAPES.

Recebido: 19/08/2009 Aprovado: 14/01/2010

Contato:

Universidade Estadual de Londrina Centro de Educação Comunicação e Artes Departamento de Educação Rodovia Celso Garcia Cid, Km 380

Campus Universitário Caixa-Postal 6001 Londrina - PR CEP 86051-990 